\title{
Challenges in the Ethical Review of Peer Support Interventions
}

\author{
David Simmons, $M D^{1,2}$ \\ Christopher Bunn, $\mathrm{PbD}^{3}$ \\ Fred Nakwagala, $M D^{4}$ \\ Monika M. Safford, MD \\ Guadalupe X. Ayala, PbD, MPH \\ Michaela Riddell, $\mathrm{PbD}^{7}$ \\ Jonathan Graffy, $M D^{8}$ \\ Edwin B. Fisher, $P b D^{9.10}$
}

'School of Medicine, University of Western Sydney, Sydney, Australia

${ }^{2}$ Institute of Metabolic Science, Cambridge University Hospitals, NHS Foundation

Trust, Cambridge, England

${ }^{3}$ Institute of Health and Wellbeing, University of Glasgow, Glasgow, Scotland

${ }^{4}$ Department of Medicine, Makerere University College of Health Sciences, Kampala, Uganda

${ }^{5}$ Department of Medicine, School of Medicine, University of Alabama, Birmingham, Alabama

${ }^{6}$ San Diego State University College of Health and Human Services and the Institute for Behavioral and Community Health, San Diego State University Research Foundation, San Diego, California

${ }^{7}$ Global Health and Society Unit, SPHPM, Monash University, Melbourne, Australia

${ }^{8}$ Department of Public Health and Primary Care, University of Cambridge, Cambridge, England

${ }^{9}$ Peers for Progress, American Academy of Family Physicians Foundation, Leawood, Kansas

${ }^{10}$ Department of Health Behavior and Health Education, Gillings School of Global Public Health, University of North Carolina, Chapel Hill, North Carolina

\section{Conflicts of interest: authors report none.}

\section{CORRESPONDING AUTHOR}

David Simmons, MD

Institute of Metabolic Science, Cambridge University Hospitals

Cambridge, England CB2

dsworkster@gmail.com

\begin{abstract}
PURPOSE Ethical review processes have become increasingly complex. We have examined how 8 collaborating diabetes peer-support clinical trials were assessed by ethics committees.
\end{abstract}

METHODS The ethical reviews from the 8 peer-support studies were collated and subjected to a thematic analysis. We mapped the recommendations of local Institutional Review Boards and ethics committees onto the " $4+1$ ethical framework" (autonomy, beneficence, non-maleficence, and justice, along with concern for their scope of application).

RESULTS Ethics committees did not consistently focus on tasks within the $4+1$ framework: many conducted reviews of scientific, organizational, and administrative activities. Of the 20 themes identified across the ethical reviews, only 4 fell within the scope of the $4+1$ framework. Variation in processes and requirements for ethics committees were particularly evident between study countries. Some of the consent processes mandated by ethical review boards were disproportionate for peer support, increased participant burden, and reduced the practicality of testing an ethical intervention. Across the 8 studies, ethics committees' reviews included the required elements to ensure participant safety; however, they created a range of hurdles that in some cases delayed the research and required consent processes that could hinder the spontaneity and/or empathy of peer support.

CONCLUSION Ethics committees should avoid repeating the work of other trusted agencies and consider the ethical validity of "light touch" consent procedures for peer-support interventions. The investigators propose an ethical framework for research on peer support.

Ann Fam Med 2015;13(Suppl_1):S79-S86. doi: 10.1370/afm.1803.

\section{INTRODUCTION}

$\eta$ he institutional mechanisms through which research programs are granted ethical clearance are becoming increasingly challenging. ${ }^{1.5}$ The process has moved from consideration of the 4 basic prima facie ethical commitments (the $4+1$ requirement) - respect for autonomy, beneficence, non-maleficence, and justice, along with concern for their scope of application ${ }^{6}$ (or in the United States, 3 ethical principles identified in the Belmont report: respect for persons, beneficence, and justice $)^{7}$ - to a more layered and detailed process, often with a far broader remit. ${ }^{8}$ The stringent requirements for gaining ethical approval carry with them the risk that research will be obstructed by excessive requirements for obtaining consent for processes with minimal risk to participants. ${ }^{9}$ Multisite research is particularly challenging. For example, a 2010 investigation suggested that a study protocol derived no scientific or ethical benefits from being scrutinized by 45 individual ethical review boards; however, preparation of applications and compliance with requested amendments cost more than $\$ 100,000 .^{10}$

The study of the health effects of peer support is of increasing interest to researchers and practitioners. Explicit recommendations for support in chronic disease self-management acknowledge that chronic disease manage- 
ment occurs primarily in the daily lives of individuals and through their own behavior. ${ }^{11-13}$ Peer support occurs when people help each other with challenges they face. Indeed, peers may be the best suited to help others implement management plans developed with their clinical teams - to help them overcome the barriers of their daily lives, the "how, not what" of daily management. ${ }^{14}$

\section{Diabetes Peer Support and the Peers for Progress Collaboration}

In a consultation on diabetes peer support in 2007, the World Health Organization brought together representatives from over 20 countries. ${ }^{15}$ Across different settings, representatives reported surprising similarities in the themes, guiding concepts, and core elements of their programs. The key themes that characterize peer support were identified as managing day-to-day living with diabetes, social and emotional support, linkage to clinical care, and the potential for an ongoing relationship. Subsequently, Peers for Progress, a program of the American Academy of Family Physicians Foundation (http://www.peersforprogress.org), funded 8 separate controlled trials across 4 countries to assess peer support for diabetes self-management ${ }^{16}$ (Table 1). Although the trials were separate, grantees agreed to collect and pool key measures to generate further findings that would benefit from the breadth and larger sample size across all sites.

Studies that test peer support pose special ethical challenges, including being conducted in the community by non-research staff who may have little familiarity with principles of research ethics. Since ethics are broadly conceived but often locally interpreted, conducting a series of studies on peer support within

Table 1. The 8 Peers for Progress Studies

\begin{tabular}{|c|c|c|c|c|}
\hline $\begin{array}{l}\text { Site Number, } \\
\text { Lead Investigator }\end{array}$ & $\begin{array}{l}\text { Country, } \\
\text { Region }\end{array}$ & Project Description & Setting & $\begin{array}{l}\text { Ethical Review } \\
\text { Structure } \\
\text { (National Bodies/ } \\
\text { Local Committee) }\end{array}$ \\
\hline 1. Ayala ${ }^{17}$ & $\begin{array}{l}\text { United States, } \\
\text { southern } \\
\text { California }\end{array}$ & $\begin{array}{l}\text { Peer-support intervention with } \\
\text { emphasis on volunteer model and } \\
\text { navigating family, community, and } \\
\text { clinical environments, among Mexi- } \\
\text { can and Mexican-American adults } \\
\text { along US-Mexico border }\end{array}$ & $\begin{array}{l}\text { Community and clinical setting; } \\
\text { coordinated by a university- } \\
\text { based research team }\end{array}$ & $\begin{array}{l}\text { FDA, DHHS, OHRP, } \\
\text { University Ethics } \\
\text { Committee }\end{array}$ \\
\hline 2. Bodenheimer ${ }^{18}$ & $\begin{array}{l}\text { United States, } \\
\text { San Francisco }\end{array}$ & $\begin{array}{l}\text { Integration of peer supporters and } \\
\text { peer coaching into nurse/doctor } \\
\text { treatment teams among clinics serv- } \\
\text { ing Latino, Caucasian, and African } \\
\text { American populations }\end{array}$ & $\begin{array}{l}\text { Community setting with tele- } \\
\text { phone and clinical links; coor- } \\
\text { dinated by a university-based } \\
\text { research team }\end{array}$ & $\begin{array}{l}\text { FDA, DHHS, OHRP, } \\
\text { University Ethics } \\
\text { Committee }\end{array}$ \\
\hline 3. Chan $^{19}$ & $\begin{array}{l}\text { China, Hong } \\
\text { Kong SAR }\end{array}$ & $\begin{array}{l}\text { Peer support, empowerment, and } \\
\text { web-based disease management } \\
\text { linked by telephone information } \\
\text { technology }\end{array}$ & $\begin{array}{l}\text { Telephone and web-based peer } \\
\text { support with community } \\
\text { components; coordinated by a } \\
\text { university-based research team }\end{array}$ & $\begin{array}{l}\text { Chinese University of } \\
\text { Hong Kong-NTEC, } \\
\text { CREC }\end{array}$ \\
\hline 4. $\mathrm{KnOx}^{20}$ & $\begin{array}{l}\text { United States, } \\
\text { Texas }\end{array}$ & $\begin{array}{l}\text { Application of a peer-support inter- } \\
\text { vention shown to be effective } \\
\text { among low-income, Latino popula- } \\
\text { tions in Los Angeles, California } \\
\text { to an older, insured, mixed-race, } \\
\text { middle-class population }\end{array}$ & $\begin{array}{l}\text { Peer-defined settings com- } \\
\text { bined with technology-based } \\
\text { interaction; coordinated by a } \\
\text { national research network in } \\
\text { partnership with community } \\
\text { groups }\end{array}$ & $\begin{array}{l}\text { FDA, DHHS, OHRP, } \\
\text { Academy Ethics } \\
\text { Committee }\end{array}$ \\
\hline 5. Oldenburg ${ }^{21}$ & $\begin{array}{r}\text { Australia, } \\
\text { Victoria }\end{array}$ & $\begin{array}{l}\text { Revision of existing NGO peer-support } \\
\text { program to focus on improved } \\
\text { daily management, linkages to } \\
\text { care, and implications for national } \\
\text { dissemination }\end{array}$ & $\begin{array}{l}\text { Non-clinical, community-based, } \\
\text { rural and urban groups; coor- } \\
\text { dinated by a university-based } \\
\text { research team }\end{array}$ & $\begin{array}{l}\text { NHMRC, AHEC, } \\
\text { University Ethics } \\
\text { Committee }\end{array}$ \\
\hline 6. Safford 22 & $\begin{array}{l}\text { United States, } \\
\text { rural Alabama }\end{array}$ & $\begin{array}{l}\text { Community-based peer advisors deliv- } \\
\text { ering one-on-one telephone coaching } \\
\text { for patient-driven self-management } \\
\text { support emphasizing empowerment. }\end{array}$ & $\begin{array}{l}\text { Predominantly African American } \\
\text { communities in rural Alabama; } \\
\text { coordinated by a university- } \\
\text { based research team }\end{array}$ & $\begin{array}{l}\text { FDA, DHHS, OHRP, } \\
\text { University Ethics } \\
\text { Committee }\end{array}$ \\
\hline $\begin{array}{l}\text { 7. Simmons and } \\
\text { Graffy }{ }^{23}\end{array}$ & $\begin{array}{l}\text { United Kingdom, } \\
\text { Cambridgeshire } \\
\text { and bordering } \\
\text { areas }\end{array}$ & $\begin{array}{l}\text { Peer-facilitated support delivered in } \\
\text { group, 1:1 or group, and 1:1 format } \\
\text { (with control group) in rural England }\end{array}$ & $\begin{array}{l}\text { Non-clinical, community-based, } \\
\text { rural and urban groups; coor- } \\
\text { dinated by a hospital-based } \\
\text { research team }\end{array}$ & $\begin{array}{l}\text { NHS, NRES, } \\
\text { Regional REC }\end{array}$ \\
\hline $\begin{array}{l}\text { 8. Tang and } \\
\text { Heisler }\end{array}$ & $\begin{array}{l}\text { United States, } \\
\text { Michigan }\end{array}$ & $\begin{array}{l}\text { Peer-led self-management support in } \\
\text { "real-world" clinical and community } \\
\text { settings among Latinos and African } \\
\text { Americans, respectively }\end{array}$ & $\begin{array}{l}\text { Clinical and community settings; } \\
\text { coordinated by a university- } \\
\text { based research team }\end{array}$ & $\begin{array}{l}\text { FDA, DHHS, OHRP, } \\
\text { University Ethics } \\
\text { Committee }\end{array}$ \\
\hline
\end{tabular}


a consortium across 4 different countries provides the opportunity to showcase the types of ethical issues that arise. This study was undertaken to compare the ethics-review experiences of the 8 separate yet collaborative research studies. We conclude by discussing whether an international set of standards could be applied to minimize variation in ethics review processes while respecting important local issues.

\section{Programmatic Global Research, IRBs, and RECs}

Global research collaborations must comply with local Institutional Review Board (IRB) and Research Ethics Committee (REC) requirements. Broadly speaking, such bodies exist to screen research proposals for their adherence to the World Medical Association Declaration of Helsinki, ${ }^{26}$ ensuring safety, protection, and disclosure of all information for participants, ensuring that proposals comply with relevant legal and clinical standards and requirements, and considering the appropriateness and acceptability of the research for the local population. Such local committees and boards are nested within national research ethics systems that provide them with infrastructural, operational, and legal frameworks.

The ethics frameworks of the 4 countries where studies funded by Peers for Progress were conducted are broadly aligned. In the United Kingdom, the National Research Ethics Service (NRES) coordinates a national network of RECs with a mission: "To protect the rights, safety, dignity and well-being of research participants; and to facilitate and promote ethical research that is of potential benefit to participants, science and society." 27

In the United States, IRBs and centralized IRBs are regulated by the Food and Drug Administration (FDA) and the Department of Health and Human Services (DHHS) through its Office for Human Research Protections (OHRP), whose mission statement is this:

.. [to provide] leadership in the protection of the rights, welfare, and wellbeing of subjects involved in research conducted or supported by the U.S. Department of Health and Human Services (HHS). OHRP helps ensure this by providing clarification and guidance, developing educational programs and materials, maintaining regulatory oversight, and providing advice on ethical and regulatory issues in biomedical and social-behavioral research. ${ }^{28}$

In Australia, the National Health and Medical Research Council (NHMRC) delegates its responsibility for ethical governance to the Australian Health Ethics Committee (AHEC), which has the following functions:

- "to advise the Council on the ethical issues relating to health"

- "to develop and give the Council human research guidelines under subsection 10(2) of the NHMRC Act"
- "any other functions conferred on the Committee in writing by the Minister after consulting the CEO"

- "any other functions conferred on the Committee by the NHMRC Act, the regulations or any other law."29

Finally, in China, ethical assessment of medical research proposals is carried out through the Chinese Clinical Trials Register (ChiCTR), which "established its own ethical committee for the linking of trial registration and ethical review." ${ }^{\prime 30,31}$

Delaying a study to address these needs can create new ethical dilemmas; in some of the 8 studies considered here, they included incorporating the relative spontaneity of peer support into the consent process for research, completing complex implementation studies in a timely fashion, and using research funding for global initiatives contemporaneously.

\section{METHODS}

Each of the 8 sites provided the report from the IRB/ REC's initial review of that site's research protocol. Each item within these reports was tabulated, collated and themed ${ }^{32}$ by a social scientist $(\mathrm{CB})$ who then mapped each theme onto 1 or more of the components of the $4+1$ framework where possible. The social scientist was not a principal investigator for any of the trials and therefore not responsible for their ethical approval.

The thematic analysis of IRB/REC reports found items that fell outside the $4+1$ framework. These were categorized under a "research governance" theme, and were subjected to additional thematic analysis. ${ }^{32}$ Themes from the IRB/REC reports were then mapped onto the emergent research governance themes, and the table of IRB/REC ethical and research governance themes was distributed to all principal investigators. Where there was discordance, the item was discussed and classified by consensus.

In addition, the principal investigators were each asked for examples of detrimental effects of the ethics review process on the research programs. These examples have been included in the text. All work was undertaken openly across the group, which included 1 ethicist (FN) who was not a principal investigator and several who serve or had served on IRB or ethics committees. The original ethics applications to the research committees were not scrutinized, as the purpose was to review the themes identified by the IRB, rather than how individual applications were written. Table 2 was generated by 1 investigator after the thematic analysis and then revised across the group.

\section{RESULTS}

Across the 8 sites, the various ethical review processes produced a mix of responses. Many of the concerns 
were extremely important and insightful. Others, however, were neither important nor insightful; they just created considerable challenges for the collaboration and its progress toward completing its research program. The itemized list of IRB themes is shown in Table 2, with associated sites not identified to maintain anonymity. Twenty specific IRB themes were identified. Of these, only 4 fell within the $4+1$ framework. They were classified as issues of non-maleficence and beneficence. These concerns focused on ensuring that peer support did not negatively impact the patient's health care or the peer supporter's wellbeing.

\section{Table 2. Issues Raised by Ethics Committees Across the 8 Peers for Progress Studies}

\begin{tabular}{|c|c|c|}
\hline Theme (No. sites affected) & Summary of IRB/REC Comments/Actions & $\begin{array}{c}\text { Research } \\
\text { Governance } \\
\text { theme }\end{array}$ \\
\hline \multicolumn{3}{|l|}{ Mapped to ethical framework $(4+1)$} \\
\hline Clinical care (3) & $\begin{array}{l}\text { Non-malevolence: Peer-support volunteers must not compromise participant medical } \\
\text { care. }\end{array}$ & \\
\hline $\begin{array}{l}\text { Clinical governance structures for } \\
\text { support staff (2) }\end{array}$ & $\begin{array}{l}\text { Beneficence: Provide further details regarding clinical governance structures to ensure } \\
\text { that research nurses report significant clinical issues to a suitably qualified clinician. }\end{array}$ & OP \\
\hline \multirow[t]{3}{*}{$\begin{array}{l}\text { Emotional support for peer sup- } \\
\text { porters (4) }\end{array}$} & $\begin{array}{l}\text { Beneficence: How will the leaders be trained to provide emotional support for group } \\
\text { members? }\end{array}$ & \\
\hline & $\begin{array}{l}\text { Beneficence: Applicants should address the emotional issues likely to arise in peer } \\
\text { support. }\end{array}$ & \\
\hline & $\begin{array}{l}\text { Beneficence: The well-being of the peer supporters should not be compromised by } \\
\text { their activities as volunteer peer supporters. }\end{array}$ & \\
\hline Questionnaire finalization (3) & $\begin{array}{l}\text { Non-malevolence: Researchers must provide a definitive questionnaire before } \\
\text { approval can be granted. }\end{array}$ & SR \\
\hline \multicolumn{3}{|c|}{ Confidentiality and privacy - not related to framework } \\
\hline Confidentiality (3) & $\begin{array}{l}\text { Arrangements for how research nurses should deal with issues relating to confidential- } \\
\text { ity should be described. }\end{array}$ & OP \\
\hline Recruitment constraints (1) & $\begin{array}{l}\text { Prospective participants identified by clinic staff must sign a card indicating interest in } \\
\text { participating before research staff contact prospective participant. }\end{array}$ & IG, OP \\
\hline $\begin{array}{l}\text { Protection of peer- supporter } \\
\text { privacy (1) }\end{array}$ & $\begin{array}{l}\text { For the protection of all concerned, volunteers should not be telephoning or visiting } \\
\text { participants late at night. }\end{array}$ & HR \\
\hline \multicolumn{3}{|c|}{ Peer-supporter characteristics/recruitment } \\
\hline \multirow[t]{2}{*}{ Selection of peer supporters (3) } & $\begin{array}{l}\text { Details relating to the recruitment, selection, vetting, training, and support of peers } \\
\text { should be given together with relevant approval time scales. }\end{array}$ & ?OP \\
\hline & Enhanced criminal and background checks must be conducted. & OP \\
\hline $\begin{array}{l}\text { Matching peer supporters to } \\
\text { peers (1) }\end{array}$ & $\begin{array}{l}\text { The abilities and qualities of the peer supporters should be matched to the needs of } \\
\text { those to be supported. }\end{array}$ & $S R$ \\
\hline $\begin{array}{l}\text { Duration and suitability of peer- } \\
\text { support training (2) }\end{array}$ & The training programs are inadequate in content and duration. & SR \\
\hline Payment for peer support (3) & $\begin{array}{l}\text { Peer supporters are being asked to give up a lot of time, and the researchers should } \\
\text { consider remuneration for this. }\end{array}$ & $\mathrm{HR}$ \\
\hline \multicolumn{3}{|c|}{ Practical safety: peers and supporters } \\
\hline \multirow{4}{*}{$\begin{array}{l}\text { Institutional protections for peer } \\
\text { supporters (2) }\end{array}$} & How will adequate support be provided for peer supporters? & $\mathrm{OP}, \mathrm{HR}$ \\
\hline & How will rescue mechanisms be provided? & $\mathrm{OP}, \mathrm{HR}$ \\
\hline & A contract should be provided for peer supporters. & OP \\
\hline & $\begin{array}{l}\text { Arrangements for how the nurse manages the peer supporters should be described, } \\
\text { particularly where a peer supporter is not functioning adequately or appropriately. }\end{array}$ & $\mathrm{OP}, \mathrm{HR}$ \\
\hline $\begin{array}{l}\text { Risk to peer or participant from } \\
\text { being alone together [at home] (1) }\end{array}$ & For 1:1 interventions, a home visiting policy is needed. & OP \\
\hline \multicolumn{3}{|l|}{ Practical safety: intervention staff } \\
\hline Antisocial working hours (1) & Nurses supporting peers should have antisocial hours limited and working hours stated. & HR \\
\hline Background checks (1) & Enhanced criminal and background checks should be required for nurses. & OP \\
\hline \multicolumn{3}{|c|}{ Study design and evaluation relating to ethical review process } \\
\hline $\begin{array}{l}\text { Separation of pilot and main study } \\
\text { approval processes (2) }\end{array}$ & Researchers must complete the pilot study before applying for approval for a full trial. & OP \\
\hline Study duration (1) & The study duration is insufficient due to the processes that will need to be followed. & OP \\
\hline $\begin{array}{l}\text { Inclusion of participant preference } \\
\text { analysis (1) }\end{array}$ & $\begin{array}{l}\text { A statistical analysis based on preference/personality of participants should be } \\
\text { carried out. }\end{array}$ & SR \\
\hline $\begin{array}{l}\text { Choice of } \mathrm{HbA}_{1 \mathrm{c}} \text { as a primary out- } \\
\text { come (1) }\end{array}$ & Is $\mathrm{HbA}_{1 \mathrm{c}}$ a suitable primary outcome for the study? & SR \\
\hline Consent form return process (1) & How will consent forms be returned to researchers? & OP \\
\hline
\end{tabular}


The 16 IRB review themes that fell outside of the $4+1$ framework generated 4 overarching themes that were constituents of research governance rather than ethics per se:

- Scientific rigor (SR): the scientific validity of the study and its organization

- Human resources (HR): how the responsible organization manages its staff

- Organizational policy (OP): how the responsible organization standardizes its operational procedures

- Information governance (IG): the appropriate, safe, and secure use of information

Across the 8 sites and 20 specific themes, there was initial disagreement over 3 specific research governance themes. After discussion, the principle investigators reached consensus, and the allocation of themes

\section{Table 3. Proposed Ethical Principles for Peer Support Research}

Honoring the dignity of persons: Any relationship between persons must be premised on an understanding and acceptance that all people have an inherent dignity that has been variously codified in international documents. Peer-support relationships must be founded on mutual respect.

Selection and training of peer supporters: This will be determined by the setting and may be through an open call for expressions of interest and/or an approach involving a person (eg, a health care professional) who is acquainted with the potential peer supporter. Information governance principles need to be adhered to in this process. The selection process for those with or without given characteristics needs to be transparent, justifiable, and fair. Peer supporters need to be trained in confidentiality. Peers have the right to confidentially refuse a given peer supporter; this may be more or less common with friends, relatives, or neighbors.

Professional-Lay boundaries: Standard professions have delineations for boundaries within which relationships may be ethically practiced. While peer supporters are not professionals, support relationships are breeched when there are conflicting roles that compete with the primary goals of peer support. This means that peer supporters need to carefully negotiate the kinds of contacts and activities they enter into with their peers.

Simplified informed consent: Implied consent may constitute an appropriate standard in two contexts: intervention and the surrounding research. Agreeing to pair up with a peer or attend a group within an IRB-approved framework should imply consent. Similarly, in certain research activities, an individual's actions imply consent (eg, completing an IRB-approved questionnaire). More intrusive research activities, however, (eg, measurements, recording of activities, and blood sampling) should require standard consent processes. Medical-record review needs to follow standard information-governance procedures.

Documentation of peer relationship and its activities: Formalizing peer relationships will require establishing some basic standards of documentation of the peer relationship and of the activities and outcomes of such a relationship. While documentation in standard professions is elaborate, standards and scope of peer documentation are not well defined. Certain critical cross-cutting issues, such as ensuring completeness and accuracy, confidentiality, avoiding falsifying of records, and truth telling, must be adhered to.

Confidentiality and privacy of personal records and information: The freedom to be left alone should extend to all peer support relationships. Patients do not have to document a written release in order to voluntarily share their own personal health information with a peer supporter. They can assume that it will be treated confidentially. They can freely choose whether to have a peer supporter and whether to share any personal health information.

Involvement in illegal activities: Parties involved in peer relationships should not abet or foster crime, including involvement with illegal drugs. Helping a peer partner in crime and covering it up is immoral and should be discouraged.

Non-licensure to practice medicine: Peer supporters are neither qualified nor licensed to diagnose, give medical advice, or recommend medications. Their interventions involve support that in many aspects aids the implementation of the licensed medical practitioner's recommendations.

Payment/Volunteerism: Any payments made to peer supporters must be carefully considered. A tension exists between the benevolence of volunteers and the capacity for health systems to exploit this benevolence which might undermine evidence-based (but more costly) structures and system changes. If a health system finances peer supporters, the system is obligated to provide adequate training and support for their work.

$\mathrm{RB}=$ institutional review board remained unchanged. Sixteen themes under Research Governance were distributed, with 4 related to scientific rigor, 8 to organizational policy, 3 to human resources, and 1 to information governance (Table 2). In contrast to those themes that fell within the $4+1$ framework, these 16 non-ethics-specific themes conport, as identified by the investigators, are listed in Table 3. Peers for Progress investigators identified potential conflicts between common concerns in ethical conduct of research on the one hand and features of peer support on the other. Concerns related to formalizing a naturally occurring social process within a formal health care setting and the perceived conflict imperative to do no harm and the practice of allowing nonprofessional peers to provide support and advice to patients with a chronic illness.

A valued feature of naturally occurring peer support is the familiarity of the provider and recipient, their shared common experiences, and their shared social contacts. As simple as the value of familiarity may seem, taking it into the domain of organized health care raises challenges to confidentiality of care and medical records.

Similarly, the credibility and persuasive power of advice and influence from peers may seem an unmixed "good," but it became problematic in the contexts of quality of care, evidencebased practice, and, again, the simple imperative to do no harm. Further, in most settings, the research required complex consent forms, which were perceived as likely to interfere with the spontaneity and informality that are valued in peer-support relationships.

\section{Detrimental Effects of IRBI REC Review on Peers for Progress Studies}

Principal investigators in the Peers for Progress consortium provided examples of increased delays, changes in protocols, and 
increases in costs resulting from IRB or REC review. In the following examples, sites have been kept anonymous where possible:

- One study was delayed by 12 months in total because the review committee required that approval for the pilot and main trials be applied for separately. The researchers considered the differences between pilot and main protocols to be small and had applied for approval of both protocols at once. ${ }^{33}$

- In another study, the IRB requirements in relation to information governance necessitated a complete change from recruiting through clinics to a community-based recruitment approach, leading to a less comprehensive trial sample and undermining investigators' ability to understand the reach of the peer-support intervention. ${ }^{34}$

- In 1 study, delays associated with implementing IRBmandated contracts, criminal record and health checks for the peer supporters were felt to have contributed to a $39 \%$ reduction in initial participation. The bureaucratic costs were borne by the host organization. The delays in this study were so great that the study duration had to be shortened for some participants from 12 months to 8 .

- One study identified the need for 3 sequential, minor amendments to the protocol. The Review Committee required them to roll the amendments into 1 at an estimated cost of $\$ 1500$ (5 hours of the Principal Investigator, 10 hours of the program manager, 1 hour of the assistant to schedule meetings and submit forms).

- The limited peer support research expertise of the ethics committees was demonstrated in one case when the committee suggested that peer supporters should be matched to peers, critiquing methods that had already been considered acceptable by scientific peer review. Indeed, the complexity of matching could have made the trial impossible and clinical implementation less feasible.

- Finally, some of the 8 collaborating sites were approved and had results, while others were still negotiating ethical approval to begin their studies. This precluded timely analysis and reporting of pooled results, which had been planned for the end of the funding period.

\section{DISCUSSION}

As our thematic analysis demonstrates, ethical review of these peer-support studies raised issues most of which were outside the $4+1$ framework, which remains the gold standard. ${ }^{35}$ Our analysis has exposed the current overlap between the roles of the sponsor, the scientific review bodies, the research and development review office, and the IRBs, especially where there are multiple sites. Ethical review bodies need to be assured that scientific/expert review of peer support research has occurred, and that robust research governance, including information governance, is in place. Repetition and duplication of such work, where it is the responsibility of other agencies, can place peer-support researchers in double jeopardy and fails to respect the worth of these bodies. This is a pressing issue that goes well beyond peer support and international studies to the daily tasks of ethics committees today. We support the recent $\mathrm{NIH}$ draft policy that recommends that $\mathrm{NIH}$ funded trials conducted at more than 1 site be approved by a single IRB ${ }^{36}$ We would propose the extension of this practice to other multicenter trials and research studies. Before the Peers for Progress dedicated funding was available, few randomized controlled trials of peer support in diabetes had been published. ${ }^{37}$ Peers for Progress used a broad-based review process that included multiple reviewers from varied disciplines and work settings. The 8 peer-support trials were selected from a highly competitive field of 101 applications. By critiquing study methodology, ethics committee reviewers were ignoring the reality that the evidence-based methods had already been subjected to scientific scrutiny during the grant review process.

Some ethics committees duplicated activities of research governance organizations. In 1 instance where a separate research-governance organization already existed, the committee concerned itself with the contractual status of peer supporters and the procurement of a particular level of criminal background checks. Ethics committees, especially if outside of the institution where the research is undertaken, are unlikely to be able to address all aspects of research governance, which also include considerations of the institutional "policies,... expertise, resources, contractual arrangements, financial issues and approach to risk management." ${ }^{138}$

Even if the ethics committee did have the required expertise, having to undergo a second scientific review and a second research governance assessment raises at least 2 major concerns. First, it leads to duplication of work and unnecessary delays in generating scientific evidence that could lead to health improvements. Second, it may introduce confusion and contradiction into the research process, as conflicting positions from authorities arise over the same issue. Both of these problems can jeopardize the successful and timely completion of research. The ethics committee that increases costs for a study by prolonging the review process or imposes requirements outside of the $4+1$ framework could affect study quality ${ }^{39}$ or divert funding from elsewhere, and that in itself could be seen as unethical. Naturally, if research governance and scientific reviews have not taken place by the time a study comes before 
an ethics review committee, or if significant changes to the protocol have occurred between the scientific and ethics reviews, the committee would need to co-opt the relevant expertise if not available on the IRB.

\section{Implications for Ethical Review of Research on Peer Support}

It is apparent that ethics committees can feel duty bound to make some changes. ${ }^{40-41}$ The experience of the 8 Peers for Progress studies offers insight into how we might better reduce the tendency for this to occur while integrating the pragmatic needs of studies, the requirements of research governance, the universal principles of ethics in global research, and the particular interests of local populations. We suggest that future investigators of socio-medical interventions construct undergirding ethical frameworks before seeking local ethical approval. We propose an example of such a framework (Table 3). Ethical frameworks like this one could be included in submissions to local IRBs and RECs. Such a process would allow global collaborations to present a unified ethical statement to local ethical authorities and thus provide a more general structure for local ethical review committees to build on. Furthermore, such a process would offer local IRBs/RECs the chance to better understand a global program's ethical positions and concerns and to make recommendations that work with the program, rather than against, it. For example, 1 solution to maintaining spontaneity of peer support would be to have IRBs review the peer support intervention, but then exempt it from certain informed consent requirements, with the clear stipulation that participants are free to accept or decline it when offered.

Ethics committees should and do play an important role in the ethical review of interventions for local populations. Our hope is that an overarching ethical framework like the one that has grown from our experience can guide global collaborations such as Peers for Progress to facilitate the local ethical review of their research on peer-support interventions.

To read or post commentaries in response to this article, see it online at http://www.annfammed.org/content/13/Suppl_1/S79.

Key words: peer support; ethics; ethics review committees; global research; diabetes

Submitted August 19, 2014; submitted, revised, April 9, 2015; accepted April 20, 2015.

Acknowledgments: We thank the Peers for Progress Principal Investigators for their provision of their ethics reports. We thank Peers for Progress for funding the various peer support trials.

Funding support: Funding for this research was provided by the American Academy of Family Physicians Foundation through the Peers for Progress program with support from the Eli Lilly and Company Foundation.

\section{REFERENCES}

1. Klitzman R. How local IRBs view central IRBs in the US. BMC Med Ethics. 2011;12:13.

2. Menikoff J. The paradoxical problem with multiple-IRB review. N Engl J Med. 2010;363(17):1591-1593.

3. Vick CC, Finan KR, Kiefe C, Neumayer L, Hawn MT. Variation in Institutional Review processes for a multisite observational study. Am J Surg. 2005;190(5):805-809.

4. Schreiner MS, Engel BC. We Have Met the Enemy and He Is Us. AJOB Primary Research. 2011;2(2):39-41.

5. Gold JL, Dewa CS. Institutional review boards and multisite studies in health services research: is there a better way? Health Serv Res. 2005;40(1):291-307.

6. Gillon R. Medical ethics: four principles plus attention to scope. BMJ. 1994;309(6948):184-188.

7. US Dept of Health and Human Services. Ethical Principles and Guidelines for the Protection of Human Subjects of Research 1979 http://www.hhs.gov/ohrp/humansubjects/guidance/belmont.html. Accessed Dec 20, 2014.

8. Smajdor A, Sydes M R, Gelling M, Wilkinson M. Applying for ethical approval for research in the United Kingdom. BMJ. 2009;339: b4013.

9. Hackshaw A, Farrant H, Bulley S, Seckl MJ, Ledermann JA. Setting up non-commercial clinical trials takes too long in the UK: findings from a prospective study. J R Soc Med. 2008;101(6):299-304.

10. Ravina B, Deuel L, Siderowf A, Dorsey ER. Local institutional review board (IRB) review of a multicenter trial: local costs without local context. Ann Neurol. 2010;67(2):258-260.

11. Fisher EB, Brownson CA, O'Toole ML, Anwuri VV. Ongoing follow-up and support for chronic disease management in the Robert Wood Johnson Foundation Diabetes Initiative. Diabetes Educ. 2007;33(Suppl 6):201S-207S.

12. Brownson CA, Heisler M. The role of peer support in diabetes care and self-management. Patient. 2009;2(1):5-17.

13. Heisler M. Different models to mobilize peer support to improve diabetes self-management and clinical outcomes: evidence, logistics, evaluation considerations and needs for future research. [retracted in Fam Pract. 2012:29(4):497]. Fam Pract. 2010;27(Suppl 1):i23-i32.

14. Davis KL, O'Toole ML, Brownson CA, Llanos P, Fisher EB. Teaching how, not what: the contributions of community health workers to diabetes self-management. Diabetes Educ. 2007;33(Suppl 6):208S-215S.

15. World Health Organization. Peer Support Programmes in Diabetes: Report of a WHO Consultation, November 2007. Geneva, World Health Organization, 2008.

16. Boothroyd RI, Fisher EB. Peers for progress: promoting peer support for health around the world. Fam Pract. 2010;27(Supplement 1): i62-i68.

17. Ayala GX, Ibarra L, Cherrington AL, et al. Puentes hacia una mejor vida (bridges to a better life): outcome of a diabetes control peer support intervention. Ann Fam Med. 2015;13(Suppl 1):S9-S17.

18. Thom DH, Ghorob A, Hessler D, De Vore D, Chen E, Bodenheimer TA. Impact of peer health coaching on glycemic control in lowincome patients with diabetes: a randomized controlled trial. Ann Fam Med. 2013;11(2):137-44.

19. Chan JC, Sui Y, Oldenburg B, Zhang Y, Chung HH, Goggins W, et al. Effects of telephone-based peer support in patients with type 2 diabetes mellitus receiving integrated care: a randomized clinical trial. JAMA Intern Med. 2014;174(6):972-81.

20. Knox L, Huff J, Graham D, et al. What peer mentoring adds to already good patient care: implementing the carpeta roja peer mentoring program in a well-resourced health care system. Ann Fam Med. 2015;13(Suppl 1):S59-S65. 
21. Oldenburg B. A controlled evaluation of the australasian peers for progress diabetes program (PfP-DP) and Its transferability to other countries.Peers for Progress website. http://peersforprogress.org/ wp-content/uploads/2014/06/20140623_oldenburg_victoria_australia.pdf. Accessed July 1, 2015.

22. Safford MM, Andreae S, Cherrington AL, et al. Peer coaches to improve diabetes outcomes in rural Alabama: a cluster randomized trial. Ann Fam Med. 2015;13(Suppl 1): S18-S26.

23. Simmons D, Prevost AT, Bunn C, Holman D, Parker RA, Cohn S, et al. Impact of community based peer support in type 2 diabetes: a cluster randomised controlled trial of individual and/or group approaches. PLoS One. 2015;10(3):e0120277.

24. Tang TS, Funnell M, Sinco B, Piatt G, Palmisano G, Spencer MS, et al. Comparative effectiveness of peer leaders and community health workers in diabetes self-management support: results of a randomized controlled trial. Diabetes Care. 2014 Jun;37(6):1525-34.

25. Tang TS, Funnell MM, Sinco B, Spencer MS, Heisler M. Peer-led, empowerment-based approach to self-management efforts In diabetes (PLEASED): a randomized controlled trial in an African American community. Ann Fam Med. 2015;13(Suppl 1):S27-S35.

26. World Medical Association. World Medical Association Declaration of Helsinki: ethical principles for medical research involving human subjects. JAMA. 2013;310(20):2191-2194.

27. NHS Health Research Authority web site. http://www.nres.nhs.uk/. Accessed Aug 15, 2013.

28. Office for Human Research Protections. US Department of Health and Human Services web site. http://www.hhs.gov/ohrp/about/mission/index.html. Accessed May 26, 2012.

29. Australian Government National Health and Medical Research Council web site. http://www.nhmrc.gov.au/about/nhmrccommittees/australian-health-ethics-committee-ahec. Accessed May 26,2012

30. Xuemei L, Youping L, Shangqi S, Senlin Y, Williams S. Ethical review reporting of Chinese trials records in WHO primary registries. J Med Ethics. 2011;37(3):144-148.
31. Wang RT, Henderson GE. Medical research ethics in China. Lancet. 2008;372(9653):1867-1868.

32. Thomas J, Harden A. Methods for the thematic synthesis of qualitative research in systematic reviews. BMC Med Res Methodol. 2008; $8: 45$.

33. Simmons D, Cohn S, Bunn C, et al. Testing a peer support intervention for people with type 2 diabetes: a pilot for a randomised controlled trial. BMC Fam Pract. 2013;14:5. 10.1186/1471-2296-14-5 http://www.biomedcentral.com/1471-2296/14/5.

34. Andreae SJ, Halanych JH, Cherrington A, Safford MM. Recruitment of a rural, southern, predominantly African-American population into a diabetes self-management trial. Contemp Clin Trials 2012; 33:499-506.

35. Page K. The four principles: can they be measured and do they predict ethical decision making? BMC Med Ethics. 2012;13:10.

36. Ethical overkill: institutions should take a unified look at protections for research on human subjects. Nature. 2014;516(7530):143-144.

37. Dale JR, Williams SM, Bowyer V. What is the effect of peer support on diabetes outcomes in adults? A systematic review. Diabet Med. 2012;29(11):1361-1377.

38. Australian Government National Health and Medical Research Council. Research governance handbook: guidance for the national approach to single ethical review. http://hrep.nhmrc.gov.au/_ uploads/files/research_governance_handbook.pdf. Published Dec 2011. Accessed Jul 3, 2015.

39. Hutton JL, Eccles MP, Grimshaw JM. Ethical issues in implementation research: a discussion of the problems in achieving informed consent. Implement Sci. 2008;3:52.

40. Fitzgerald $M H$, Phillips PA, Yule E. The research ethics review process and ethics review narratives. Ethics Behav. 2006;16(4):377-395.

41. Stark LJM. Behind Closed Doors: IRBs and the Making of Ethical Research. Chicago, IL: The University of Chicago Press;2012. 